\title{
Follow-up after acute Pulmonary Embolism
}

\section{Predicting chronic thromboembolic pulmonary hyperten- sion and post-pulmonary embolism syndrome}

\author{
Frederikus A. Klok ${ }^{1,2}$; Stefano Barco ${ }^{1}$ \\ ${ }^{1}$ Center for Thrombosis and Hemostasis, University Hospital of the Johannes Gutenberg University Mainz, Mainz, \\ Germany; ${ }^{2}$ Department of Thrombosis and Hemostasis, Leiden University Medical Center, Leiden, the Netherlands
}

\author{
Keywords \\ Pulmonary embolism, CTEPH, post-PE syn- \\ drome, quality of life
}

\section{Summary}

In addition to among others major bleeding from anticoagulant therapy and recurrent venous thromboembolism (VTE), patients who survived acute pulmonary embolism (PE) face an increased risk of chronic functional limitations and decreased quality of life. In recent years, this latter complications have been better framed within the evolving defi-

\section{Correspondence to}

F.A. Klok

Department of Thrombosis and Hemostasis,

LUMC,

Albinusdreef 2,

2300 RC Leiden

Email: f.a.klok@LUMC.nl nition of "post-PE syndrome" of which chronic thromboembolic pulmonary hypertension (CTEPH) represents the most extreme presentation. The post-PE syndrome in all its aspects is a frequent and clinically relevant long-term complication of PE but -except for CTEPH- has been largely understudied. There is great need to better define and understand the natural course of acute PE, to predict the development of the post-PE syndrome and to evaluate the potential benefits evolving treatments such as cardiopulmonary rehabilitation.

Nachsorge bei akuter Lungenembolie Vorhersage einer chronisch thromboembolischen pulmonalen Hypertonie und eines chronischen Lungenembolie-Syndroms

Hämostaseologie 2018; 38: 22-32

https://doi.org/10.5482/HAM0-17-06-0020 received: June 20, 2017

accepted in revised form: December 11, 2017

\section{Funding}

Frederikus Klok reports research grants from Bayer, research grants from Bristol-Myers Squibb, research grants from Boehringer-Ingelheim, research grants from MSD and non-financial research support from Daiichi-Sankyo. Stefano Barco has received congress and travel payments from Daiichi-Sankyo and Bayer HealthCare. The work of Frederikus Klok and Stefano Barco is supported by the German Federal Ministry of Education and Research (BMBF 01 E01003 and 01E01503).

Authorship statement

Both authors have contributed significantly to and approve of this manuscript.

\section{Schlüsselwörter}

Lungenembolie, CTEPH, chronisches Lungenembolie-Syndrom, Lebensqualität

\section{Zusammenfassung}

Über Komplikationen wie größere Blutungen infolge der Antikoagulation oder rezidivierende venöse Thrombembolien (VTE) hinaus, haben Patienten, die eine akute Lungenembolie (LE) überlebt haben, ein erhöhtes Risiko für chronische funktionelle Einschränkungen und eine reduzierte Lebensqualität. Letztere werden neuerdings in dem aufkommenden Begriff des chronischen LE-Syndroms („ "PostLE-Syndrom") zusammengefasst, das seine extremste Ausprägung in der chronisch thromboembolischen pulmonalen Hypertonie (CTEPH) findet. Das chronische LE-Syndrom in all seinen Aspekten ist eine häufige und klinisch relevante Langzeitkomplikation der $\mathrm{LE}$, wurde jedoch - mit Ausnahme der CTEPH - nur unzureichend untersucht. Es ist dringend erforderlich, den natürlichen Verlauf einer akuten LE besser zu definieren und zu verstehen, um die Entwicklung eines chronischen LE-Syndroms vorherzusagen und den potenziellen Nutzen neuer Behandlungsformen, wie der kardiopulmonalen Rehabilitation, zu evaluieren.

\section{Introduction}

After surviving acute pulmonary embolism $(\mathrm{PE})$, patients face an increased risk of developing major bleeding from anticoagulant therapy, recurrent venous thromboem- bolism (VTE), arterial cardiovascular diseases, or chronic functional limitations (1-8). In recent years, this latter complication has been better framed within the evolving definition of "post-PE syndrome", which accounts for suboptimal cardiac function, pulmonary artery flow dynamics, or pulmonary gas exchange at rest or during exercise, in combination with symptoms of exercise intolerance, dyspnea, impaired functional status, or worsened quality of life $(8,9)$. Chronic thromboem- 
bolic pulmonary hypertension (CTEPH) represents the most severe manifestation of the post-PE syndrome (10-12). In the present review, we discuss the pathophysiology and frequency of CTEPH and post-PE syndrome, as well as the strategies under development to predict, prevent, and treat long-term sequelae of acute PE.

\section{Chronic thromboembolic pulmonary hypertension \\ Pathophysiology of CTEPH}

A commonly accepted mechanistic hypothesis is that CTEPH results from an incident episode of 'unresolved' PE characterized by the persistence of residual thrombi despite anticoagulant therapy, which contributes to increase pulmonary vascular resistance and ultimately results in progressive right ventricular overload (13-15). The exact pathophysiological mechanism that may prevent from complete resolution of acute thrombus is however not fully clarified yet, although pro-inflammatory state, abnormal fibrinogen variants, aberrations in angiogenesis, and mesenchymal cell activation have been implicated in poorer pulmonary thrombus resolution (Table 1) (13-21). Notably, whereas radiological signs of unresolved thrombotic material are necessary criteria for confirming a CTEPH diagnosis, these do not always match with the severity of the clinical presentation of individual patients and therefore cannot be accounted as an indicator for prognosis. In addition to chronic blood clots, CTEPH patients usually exhibit widespread pulmonary microvasculopathy, which resembles that of other pulmonary arterial hypertension subtypes (13, 22-24). Diffuse areas of the lung-affected or not by chronic thrombotic occlusions- similarly manifest microvasculopathy, indicating that higher share stress caused by chronic thrombi is not solely responsible for arterial remodeling. One of the explanations that has been hypothesized is that microvascular changes may be caused by altered blood flow from multiple anastomoses between systemic and pulmonary circulation through hypertrophic bronchial arteries that are opened by the high pressure gradient which develops between bronchial and pulmonary arteries affected by chronic blood clots (22).

Indeed, both the small vessel disease and the chronic proximal obstruction of the pulmonary arteries contribute to the progression of right ventricular overload. Initially, this outflow burden leads to right ventricular hypertrophy as a mechanism of the heart in order to increase the effectiveness of its pumping function, a process also referred to as 'adaptive remodeling.(25) However, adaptive remodeling is associated with a maintained right ventricular func-

Tab. 1 Summary of the pathophysiological mechanisms implicated for the transition of acute PE to CTEPH and clinical conditions which may "predispose" to CTEPH

\begin{tabular}{|c|c|}
\hline $\begin{array}{l}\text { Clinical conditions implicated with a } \\
\text { higher risk of CTEPH }\end{array}$ & $\begin{array}{l}\text { Known mechanisms of thrombus nonresol- } \\
\text { ution implicated with CTEPH pathophysiology }\end{array}$ \\
\hline Thyroid replacement therapy & Defective angiogenesis \\
\hline Malignancy & Systematic inflammation \\
\hline (Recurrent) Venous thromboembolism & Fibrinogen abnormalities/impaired fibrinolysis \\
\hline Antiphospholipid antibodies & Misguided immune response to venous clots \\
\hline High FVIII & $\begin{array}{l}\text { Hypoxia-induced endothelial and mesenchymal } \\
\text { cell activation }\end{array}$ \\
\hline \multicolumn{2}{|l|}{ Non-O blood group } \\
\hline \multicolumn{2}{|l|}{ Ventriculo-atrial shunt } \\
\hline \multicolumn{2}{|l|}{ Infected pacemaker leads } \\
\hline \multicolumn{2}{|l|}{ Indwelling venous catheters and leads } \\
\hline \multicolumn{2}{|l|}{ Splenectomy } \\
\hline Chronic inflammatory disorders & \\
\hline
\end{tabular}

tion for a limited period of time, after which inevitably 'uncoupling' occurs, causing right ventricular dilatation and -especially during exercise- insufficiency, which ultimately lead to terminal right ventricular failure and death $(25,26)$.

\section{How often is CTEPH diagnosed after acute PE?}

The incidence of CTEPH after symptomatic acute $\mathrm{PE}$ has been reported to range from $0.1 \%$ to $11.8 \%$, with most studies showing a frequency of 2-4\% (10, 27-36). Beyond geographic or historical variations, such wide range can be explained by differences in patient selection and diagnostic criteria adopted by the investigators of published studies. For instance, most studies focused on specific subgroups of PE patients characterized by the absence of cardiopulmonary comorbidities and some did not apply right heart catheterization to confirm CTEPH.

To provide more clarity, a systematic review and meta-analysis of relevant studies and meeting abstracts has been recently published (37). Studies adopting invasive measurements to confirm the diagnosis of CTEPH were included in the main analysis and three patient subgroups were predefined to limit heterogeneity, namely i) 'all comers' (unselected consecutive PE patients), ii) 'survivors' (PE patients who survived the first three to six months), and iii) 'survivors without comorbidities' (survivors further selected by excluding patients with cardiopulmonary, malignant and/or other severe comorbidities). A total of 4,047 PE patients were evaluated in the meta-analysis for pooled incidences in the predefined cohorts of $0.56 \% \quad(95 \% \mathrm{CI}$ $0.1-1.0$ ), 3.2\% (95\%CI 2.0-4.4), and $2.8 \%$ (95\%CI 1.5-4.1), respectively ( Figure 1) (37).

Notably, the comparable incidences of both 'survivor' cohorts indicated that the presence of other conditions that may explain symptoms of functional impairment and dyspnea, such as COPD, do not appear to rule out the diagnosis of CTEPH, and adequate diagnostic tests for CTEPH should not be withheld in such patients. A final important observation of the metaanalysis regards the clear overdiagnosis of 
CTEPH in studies that did not apply right heart catheterization but echocardiography as the diagnostic standard for CTEPH with a 3-fold higher CTEPH incidence $(9.1 \%$, $95 \%$ CI 4.1-14), indicating that echocardiography is not an accurate standalone test to confirm this diagnosis.

It must be noted however that the cases of CTEPH reported in the aforementioned follow-up studies likely represent a mix of incident and prevalent cases, therefore overestimating the actual figures of $\mathrm{CTEPH}$ incidence, since the diagnosis of CTEPH was often made within a few months after the index PE. In particular, a highly cited French study reported detailed reevaluation of the clinical $\mathrm{PE}$ presentation of the 7 (of 146) PE patients who were diagnosed with CTEPH (33). In five of seven patients, the authors described a notable elevated (assessed via echocardiography) systolic pulmonary arterial pressure of $70 \mathrm{mmHg}$, while historical data suggested that acute PE can be associated with an increase in mean pulmonary artery pressure of up to $40 \mathrm{mmHg}$ only with an extensive $70 \%$ of the pulmonary artery tree occluded by blood clots (38). This observation would suggest that these five patients may have developed pulmonary hypertension before the PE diagnosis was confirmed. Indeed, after review of the initial CTPA images by an expert radiologist, all seven patients had at least two signs of the condition at initial acute PE presentation, as did $20 \%$ of patients who did not develop CTEPH during the median follow up of 26 months. Based on the latter observation, it could be hypothesized that preexisting (prevalent) CTEPH would have been misclassified as acute PE in some or even all the patients eventually diagnosed with CTEPH over follow-up. Nevertheless, as long as it remains impossible to distinguish 'true' acute PE from CTEPH at a (sub)acute clinical presentation, the difference between prevalent and incident cases of CTEPH after acute PE does not appear of clinical relevance for the initial treatment of these patients since all are candidate to extended anticoagulation, nor for determining the proper level of awareness for CTEPH of PE caretakers.

To further reinforce this concept, several observations demonstrated that
Fig. 1

Pooled incidence of chronic thromboembolic pulmonary hypertension in three predefined patient subcategories (reprinted with permission [37])

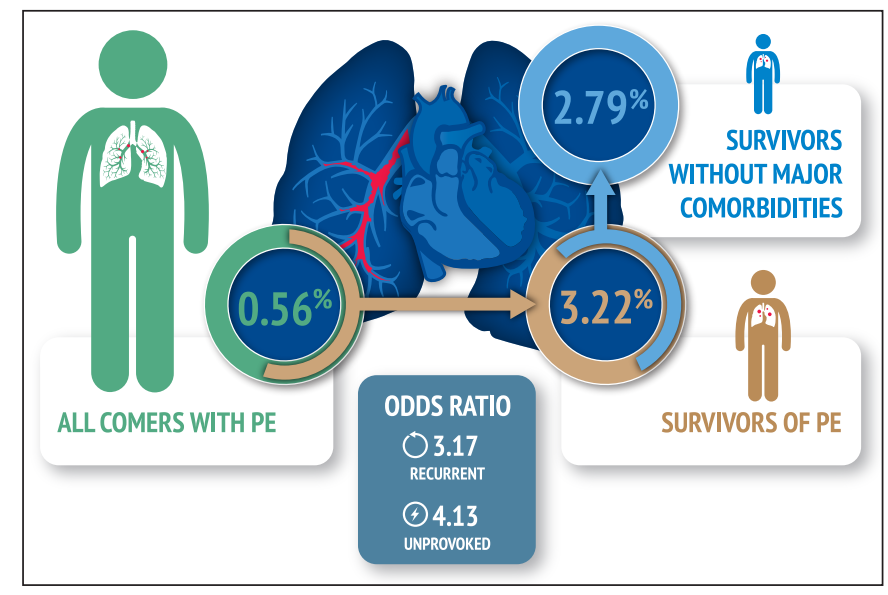

CTEPH is not preceded by symptomatic VTE in $19-63 \%$ of patients $(39,40)$. It remains purely speculative the hypothesis of these patients suffering from episodes of 'silent PE', or, alternatively, if they represent a different clinical scenario of CTEPH developing from in situ thrombosis as a thrombogenic phenotype of class 1 pulmonary hypertension.

\section{Can we predict CTEPH?}

The ability to predict which PE patients will develop CTEPH will likely improve their prognosis by allowing physicians to better apply valuable resources to a specific high-risk group, while preventing unnecessary imaging tests to patients with a negligible risk of developing or having CTEPH. Unfortunately, evidence for strategies of risk prediction are scarce and this is largely due to the absolute low incidence of the disease and the unavailability of large databases of consecutive patients at risk of developing CTEPH $(41,42)$.

One possible strategy to overcome these limitations would be to focus on cohorts of PE patients with identified risk factors for CTEPH such as splenectomy, prior infected pacemaker leads, chronic inflammatory disease, antiphospholipid syndrome, known hypothyroidism, and ventriculo-atrial shunt ( Table 1) (43-46). The first issue that may raise by adopting this approach is represented by the fact that these variables have been identified as risk factors associated with CTEPH, but not validated as predictors of the disease and therefore cannot be used (yet) for a first risk stratification in order to increase the expected rate of CTEPH in the study cohort. Moreover, the absolute risk of CTEPH for patients presenting with these risk factors is unknown as they were often identified in case-control studies comparing subjects diagnosed with CTEPH and population controls or patients with class 1 $\mathrm{PH}$, and not in cohorts of PE survivors (47). Finally, since their prevalence in PE cohorts is low (e.g. for splenectomy about $2 \%$ ), this approach appears unlikely to be sufficiently accurate.

A second strategy would be to study the added value of reassessing CTPA scans for detecting signs of chronic PE or pulmonary hypertension such as right ventricular hypertrophy, webs and bands, tortuous bronchial arteries or mosaic perfusion (33). As discussed above, these signs may be very sensitive for prevalent CTEPH. Even so, the afore mentioned French study included only seven patients with CTEPH and does not provide sufficient evidence for strong recommendations for clinical practice.

Clinical decision rules and risk assessment models are widely used in clinical practice for diagnostic or prognostic purposes. A collaborative study between German, Polish and Dutch PE expert centers aimed at developing a score for prediction of CTEPH after PE (47). They performed a patient-level analysis of a total of $772 \mathrm{PE}$ survivors without major cardiopulmonary or oncological comorbidities at baseline, and fit multivariate regression models to identify clinical variables easily assessable at the time of index PE event that would independently predict CTEPH. A score con- 


\begin{tabular}{l|c}
\hline & $\begin{array}{l}\text { Points for } \\
\text { score }\end{array}$ \\
\hline Unprovoked PE & +6 \\
\hline Known hypothyroidism & +3 \\
\hline Symptom onset > 2 weeks before PE diagnosis & +3 \\
\hline Right ventricular dysfunction on CT or echocardiography & +2 \\
\hline Known diabetes mellitus & -3 \\
\hline Thrombolytic therapy or embolectomy & -3 \\
\hline
\end{tabular}

Note: $\mathrm{PE}=$ pulmonary embolism; $\mathrm{CT}=$ computed tomography; $\mathrm{VTE}=$ venous thromboembolism.

sisting of six variables was derived ( Table 2), the so-called 'CTEPH prediction score'. Approximately, $75 \%$ of patients was classified as 'low-risk' with a PE incidence during follow-up of $<0.5 \%$, and one quarter as 'high-risk with' a CTEPH incidence of $10 \%$. The overall predictive value of the score was good with an area under the receiver operator characteristic curve (ROC) in both the primary as well as the sensitivity analysis of $>0.85$ (47). External validation of the CTEPH prediction score is not yet available. Interestingly, the score provides two striking variables that seemed to 'protect' against CTEPH, namely thrombolysis and diabetes, which must be confirmed for their pathophysiological role in future studies.

\section{Can we prevent CTEPH?}

Thrombolysis was recently been shown not to protect against CTEPH development in a follow-up study including a large proportion of patients with acute PE associated with right ventricular dysfunction on echocardiography or computed tomography, as well as positive laboratory markers for myocardial injury, previously enrolled in the Pulmonary Embolism Thrombolysis (PEITHO) trial (5). Additionally, the European CTEPH registry, which also includes patients treated with thrombolysis, indicated that reperfusion therapy does not prevent the development of CTEPH $(39,48)$. The main 'methodological' reason for which thrombolytic treatment was included in the score is the fact that, although only 22 patients who developed the outcome (CTEPH) were included in this study, none received throm-
Tab. 2 CTEPH prediction score (47); a score of more than 6 points denotes a 'high risk'. bolysis, which may have been due to chance or to the presence of biases for selection, indication, or reporting intrinsic to the observational study design of the derivation cohorts. Whether lysed (high-risk) patients are less likely to suffer from more chronic thromboembolic disease remains to be proven.

The other notable factor that was negatively associated with the presence of CTEPH was diabetes mellitus. It was nonetheless previously shown that patients with class 1 pulmonary hypertension more often have Diabetes than patients with CTEPH $(43,44,49)$. One possible explanation for these independent observations would be that metformin, which is the first line treatment of type 2 diabetes mellitus, has pro-fibrinolytic properties by reducing the activity of plasminogen activator inhibitor-1 $(50,51)$. Indeed, use of metformin has been reported to be associated with a lower risk of venous thromboembolism in cohort study of moderate quality (52).

\section{Post-PE syndrome}

\section{Does a "Post-PE syndrome" exist?}

The frequency of functional impairment after acute PE was evaluated in several cohort studies. In a prospective study of 109 previously healthy patients experiencing incident acute PE, more than half (53\%) reported symptoms of exercise intolerance corresponding to a New York Heart Association (NYHA) heart failure score of $\geq$ II after a 6-month follow-up period.(53) A second study in $162 \mathrm{PE}$ survivors showed similar figure $(52 \%)$ of persisting symptoms (NYHA score of II or more) six months after PE diagnosis and anticoagulant treatment initiation (54). Similarly, a third study found a 3-year NYHA incidence rate of class II (or higher classification) of $45 \%$ among 189 PE survivors (55). If one focuses on severe functional limitations only (i.e. NYHA class III/IV and/or impaired 6-minute walking test), the resulting percentages are of $41 \%$ and $42 \%$, respectively $(53,54)$. Initial follow-up data suggest that 6-minute walking test may improve up to one year after PE diagnosis, although most improvement occurs in the first three months (8). Based on a recent meta-analysis that included the aforementioned studies as well as smaller cohort studies, the pooled prevalence of mild or greater functional impairment (NYHA II-IV) in PE survivors is $33.2 \%$ (95\%CI 21.3-46.4) after a median follow-up duration of 40 months (56). While CTEPH is a rare condition, this phenomenon must be explained by another pathophysiological mechanism ( Figure 2) (9).

The condition of persistent perfusion defects without resting pulmonary hypertension (mean pulmonary systolic pressure $>25 \mathrm{mmHg}$ ) has been previously referred to as chronic thromboembolic vascular disease (CTED) when associated with functional impairment: CTED falls under the umbrella of the post-PE syndrome $(9,57)$. In one study, patients with CTED were found to have gas exchange disturbances and ineffective ventilation to a similar degree as can be found in patients with CTEPH (57). The mechanism for functional impairment in CTED may be heterogeneous and includes exercise-induced pulmonary hypertension, ventilatory dead space, right ventricular dysfunction (e.g. decreased contractile reserve), and abnormal pulmonary flow dynamics (e.g. running pressure wave reflection). The most frequent cause of the post-PE syndrome may however very well be deconditioning after an acute cardiovascular disease with associated hospitalization and correlated burden $(8,59)$.

\section{Impact of CTEPH and the post-PE syndrome}

CTEPH, but not the less severe presentations of the post-PE syndrome, has been 


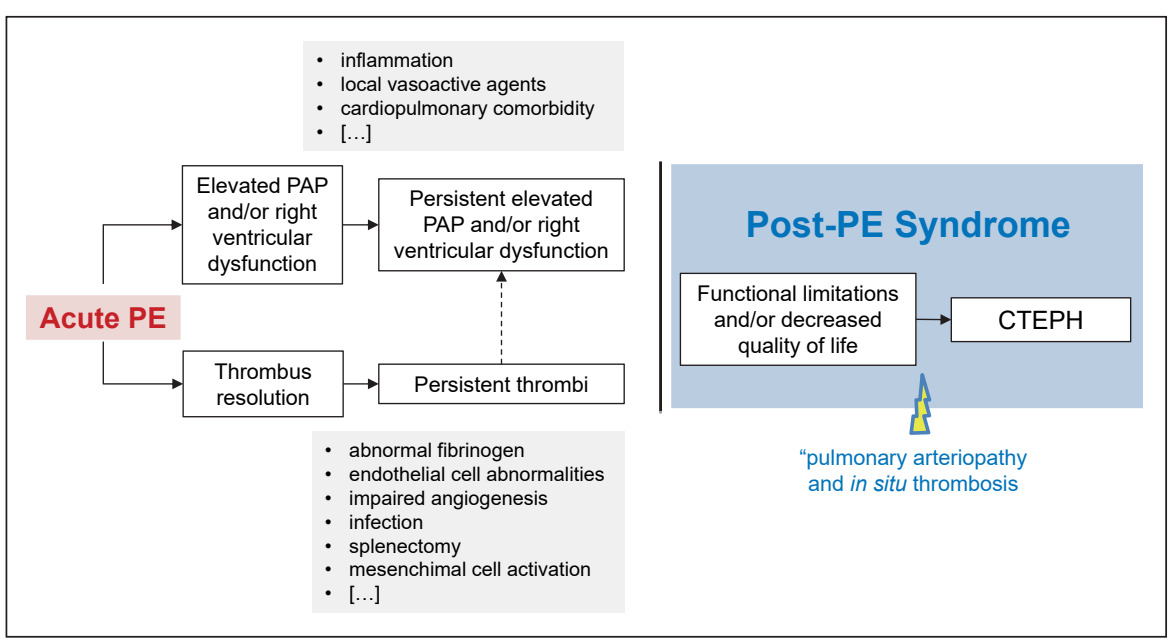

Fig. 2 Overview of post-pulmonary embolism syndrome, adjusted from (9) with permission.

associated with increased risk of death. Historical data indicate that 5-year survival after CTEPH diagnosis is as poor as $20 \%$ in patients with pulmonary artery pressures $>50 \mathrm{mmHg}$ if adequate treatment is not provided (60). More recent data in all-severity pulmonary hypertension patients showed a 5-year survival rate of $70 \%$, with marked better prognosis in those who underwent pulmonary endarterectomy (PEA), which is still indicated as the firstline treatment of CTEPH (39).

In general, patients with post-PE syndrome have lower score measured by quality of life questionnaires compared with population controls or with PE patients who report full recovery $(7,61,62)$. Poorer quality of life has been demonstrated to be greatly dependent on functional impairment and correlates with poor physical performance on exercise testing. Other factors being possibly associated with worse quality of life include higher clot burden at index PE event, abnormal NT-proBNP at index PE event, persistent right ventricular dysfunction, as well as non-VTE comorbidities such as COPD obesity and cancer $(8,55,59,63-70)$. As it may be expected, the association between CTEPH and poor quality of life has been unequivocally established (71-74).

\section{Treatment and prevention of CTEPH and the post-PE syndrome}

The gold standard treatment for CTEPH is PEA, which has been shown to reduce mortality and improves right circulation hemodynamics as well as exercise tolerance in prospective studies. During this surgical procedure, thromboembolic material is removed from the pulmonary artery tree after median sternotomy and during deep hypothermic circulatory arrest $(75,76)$. Postoperative hemodynamics become normal or near normal in most patients after PEA with an average $65 \%$ decrease in pulmonary artery resistance and a sharp decrease in mean pulmonary artery pressure. In high-volume centers, the in-hospital mortality currently is lower than $5 \%$ ( 75 , 76). PEA is not an established therapeutic option for CTED since such death risk overcomes possible benefits: despite that, surgery is sometimes performed for this indication. In fact, a small cohort study including 42 patients undergoing PEA for CTED demonstrated a significant improvement in NYHA functional status, mean pulmonary artery pressure, pulmonary vascular resistance, 6-minute walk distance, and quality of life at cost of major complications such as supraventricular tachycardia's, re-surgery or re-intubation occurring in up to $40 \%$ of patients (77). Hence, on a risk-benefit balance, PEA should not be routinely performed in CTED patients, but may be considered in individual cases based on the extend of the thrombotic lesions, gas exchange abnormalities, severity of symptoms, and patient's preferences.

Due to extensive distal CTEPH or severe comorbidities, a not-negligible subset of patients is considered inoperable and must be considered for the sole medical and support therapy. A trial of Riociguat, a soluble oral stimulator of guanylate cyclise, showed to improve 6-minute walk distances and reduce pulmonary vascular resistance in inoperable CTEPH patients (78). Based on a growing number of observation of its effectiveness, Riociguat is currently the only approved medical therapy for inoperable CTEPH (78-81). Off-label use of other pulmonary hypertension drugs (e.g. bosentan, iloprost, and prostacyclin), or the use of riociguat as a therapeutic bridge to PEA, is currently not recommended mostly based on unavailable data (81). Similarly, its benefit in patients with post-PE syndrome have never been studied and therefore Riociguat remains contra-indicated, despite some rationale for its use in this setting.

A catheter-based approached, balloon pulmonary angioplasty (BPA), is being explored at several centers for patients who do not match surgical suitability with PEA. In this procedure, small angioplasty balloons are introduced into segmental pulmonary artery branches and used to dilate webs and strictures (82-86). This procedure was firstly performed in a Dutch patient in 1988, who developed non-lethal pulmonary edema after two procedures (87). In the past decades, the technique of BPA has been much improved in Japan and re-introduced in Europa and NorthAmerica in recent years. While preliminary results indeed are promising, solid randomized studies are needed to define BPA's efficacy and the place of BPA in the treatment algorithm of CTEPH. As with medical treatment, although patients with CTED may also benefit from BPA, BPA has never been systematically evaluated in this specific patient group.

Unlike patients with myocardial infarction or other severe cardiopulmonary conditions, cardiopulmonary rehabilitation is not routinely offered to patients with a PE diagnosis, nor to patients with post-PE syndrome. However, available data -although scarce- suggest the effectiveness of such intervention in patients with PE (88, 89) or with an established CTEPH diagnosis (90-92) in terms of exercise parameters and quality of life. Although these pre- 
liminary data suggest a benefit of cardiopulmonary rehabilitation for patients with the post-PE syndrome, future larger randomized outcome studies will establish the relevance and cost-effectiveness of such approach. Importantly, for patients with $\mathrm{CTEPH}$, cardiopulmonary rehabilitation programs should not delay PEA if patients are operable.

\section{How should patients be followed after acute PE?}

Practice patterns of patient follow-up after acute PE differ greatly and solid evidence to provide guidance is lacking. The only strong guideline recommendations from different international guidelines is that all patients with acute PE need to be treated with a 3-month minimum course of anticoagulant therapy, after which the net clinical benefit of secondary anticoagulant prevention accounting for bleeding risk should be reassessed (81). This routine 3-month follow-up visit would be the ideal timeframe for the assessment risk factors for post-PE syndrome and specifically CTEPH. We propose that in all patients at an estimated high risk of CTEPH, based on i) clinical and radiological characteristics of index PE and persistent RV dysfunction at discharge, ii) CTEPH prediction score (as described above), or iii) clear functional impairment, the presence of CTEPH should be evaluated. Importantly, subjecting all PE survivors routinely to echocardiography or ventilation perfusion scintigraphy has a low diagnostic yield, leads to gross overdiagnosis and is not cost-effective. Hence, such practices need to be abandoned. Since it may take much longer than three months for CTEPH to develop, patients as well as PE caretakers should be educated to be aware of this long term complication: CTEPH should be included in the deferential diagnosis of patients who develop chronic dyspnea or functional impairment in the longer-term follow-up after PE, regardless of the presence of other cardiopulmonary comorbidities.

\section{Future landscape}

Four key clinical studies that will definitely change the landscape of post-PE care in- clude the FOCUS study, the InShape II study, a Danish rehabilitation study and the RACE study. The FOCUS study is a large prospective observational German cohort study of PE patients (German Clinical Trials registry: DRKS00005939). In FOCUS, a total of 1000 PE patients are systematically followed over a 2-year period with a standardized comprehensive program of clinical, echocardiographic, functional and laboratory testing. This study will provide definite answers to relevant remaining questions such as the occurrence of CTEPH and temporal patterns of and risk factors for post-PE abnormalities. Moreover, it will contribute to better standardize the concept of post-PE syndrome by adopting predefined diagnostic definition including clinical symptoms and advanced imaging criteria (93).

The InShape II study is an international, multicenter intervention study that will prospectively validate a PE follow-up algorithm aimed at early diagnosis of CTEPH (ClinicalTrials.gov: NCT02555137). The algorithm consists of sequential application of the CTEPH prediction score, followed by the so called 'rule-out criteria' for patients with either a high clinical probability for CTEPH or with specific symptoms of CTEPH $(47,94,95)$. The 'rule-out criteria' consist of NT-proBNP measurement and ECG assessment for 3 specific signs of pulmonary hypertension. Only patients with either elevated NT-proBNP or those with 1 of the 3 ECG signs present will be referred for CTEPH diagnostic tests, limiting the number of necessary imaging tests and false-positive test results. The main endpoints of the InShape II study are the sensitivity of the algorithm, i.e. the number of missed CTEPH diagnoses after 2-year follow-up, and the cost-effectiveness of the algorithm.

The first large randomized controlled trial to assess the benefit of pulmonary rehabilitation in PE patients is being performed in Denmark (ClinicalTrials.gov: NCT02684721). The aim of this study is to examine whether an 8-week home-based exercise intervention may improve physical capacity, quality of life, sick leave, and use of psychotropic drugs in patients with a history of acute PE (96). This important study will provide sufficient evidence on the question whether cardiopulmonary rehabilitation may be a relevant treatment for the post-PE syndrome, allowing for many further clinical trials to determine the optimal rehabilitation program.

The RACE study (ClinicalTrials.gov: NCT02634203) is a randomized open-label clinical trial, in which patients with CTEPH who are not eligible for PEA will be randomised to riociguat or BPA as firstline treatment. The primary aim of the study is to establish the difference in change in pulmonary vascular resistance from baseline to the end of the 26-week follow-up period. This study will show us whether medical treatment or BPA may be the better first-line treatment option in non-operable CTEPH patients.

\section{Conclusion}

The post-PE syndrome in all its aspects is a frequent and clinically relevant long-term complication of acute PE. Except for CTEPH, its most severe manifestation, the post-PE syndrome remains largely understudied. In addition to the optimal treatment approach for non-operable CTEPH, there is great need to better define and understand the natural course of acute PE and to predict its development, as well as to extensively evaluate the potential benefits of BPA, medical treatment, and cardiopulmonary rehabilitation for patients with the post-PE syndrome.

\section{Disclosures}

Frederikus Klok reports research grants from Bayer, research grants from BristolMyers Squibb, research grants from Boehringer-Ingelheim, research grants from MSD and non-financial research support from Daiichi-Sankyo. Stefano Barco has received congress and travel payments from Daiichi-Sankyo and Bayer HealthCare.

\section{Reference List}

1. Linkins LA, Choi PT, Douketis JD. Clinical impact of bleeding in patients taking oral anticoagulant therapy for venous thromboembolism: a metaanalysis. Ann Intern Med 2003; 139: 893-900. 
2. Klok FA, Zondag W, van Kralingen KW, van Dijk AP, Tamsma JT, Heyning FH, et al. Patient outcomes after acute pulmonary embolism. A pooled survival analysis of different adverse events. Am J Respir Crit Care Med 2010; 181: 501-506.

3. Prandoni P, Noventa F, Ghirarduzzi A, Pengo V, Bernardi E, Pesavento R, et al. The risk of recurrent venous thromboembolism after discontinuing anticoagulation in patients with acute proximal deep vein thrombosis or pulmonary embolism. A prospective cohort study in 1,626 patients. Haematologica 2007; 92: 199-205.

4. den Exter PL, van der Hulle T, Lankeit M, Huisman MV, Klok FA. Long-term clinical course of acute pulmonary embolism. Blood Rev 2013; 27: 185-192.

5. Konstantinides SV, Vicaut E, Danays T, Becattini C, Bertoletti L, Beyer-Westendorf J, et al. Impact of Thrombolytic Therapy on the Long-Term Outcome of Intermediate-Risk Pulmonary Embolism. J Am Coll Cardiol 2017; 69: 1536-1544.

6. Klok FA, Mos IC, Broek L, Tamsma JT, Rosendaal FR, de RA, et al. Risk of arterial cardiovascular events in patients after pulmonary embolism. Blood 2009; 114: 1484-1488.

7. Klok FA, van Kralingen KW, van Dijk AP, Heyning FH, Vliegen HW, Kaptein AA, et al. Quality of life in long-term survivors of acute pulmonary embolism. Chest 2010; 138: 1432-1440.

8. Kahn SR, Akaberi A, Granton JT, Anderson DR, Wells PS, Rodger MA, et al. Quality of Life, Dyspnea, and Functional Exercise Capacity Following a First Episode of Pulmonary Embolism: Results of the ELOPE Cohort Study. Am J Med 2017.

9. Klok FA, van der Hulle T, den Exter PL, Lankeit M, Huisman MV, Konstantinides S. The post-PE syndrome: a new concept for chronic complications of pulmonary embolism. Blood Rev 2014; 28: 221-226.

10. Pengo V, Lensing AW, Prins MH, Marchiori A, Davidson $\mathrm{BL}$, Tiozzo F, et al. Incidence of chronic thromboembolic pulmonary hypertension after pulmonary embolism. N Engl J Med 2004; 350: 2257-2264.

11. Kim NH, Delcroix M, Jenkins DP, Channick R, Dartevelle P, Jansa P, et al. Chronic thromboembolic pulmonary hypertension. J Am Coll Cardiol 2013; 62: D92-D99.

12. Lang IM, Madani M. Update on chronic thromboembolic pulmonary hypertension. Circulation 2014;130:508-18.

13. Simonneau G, Torbicki A, Dorfmuller P, Kim N. The pathophysiology of chronic thromboembolic pulmonary hypertension. Eur Respir Rev 2017; 26.

14. Morris TA. Why acute pulmonary embolism becomes chronic thromboembolic pulmonary hypertension: clinical and genetic insights. Curr Opin Pulm Med 2013; 19: 422-429.

15. Lang IM, Dorfmuller P, Vonk NA. The Pathobiology of Chronic Thromboembolic Pulmonary Hypertension. Ann Am Thorac Soc 2016; 13 (Suppl. 3): S215-S221.

16. Bochenek ML, Rosinus NS, Lankeit M, Hobohm L, Bremmer F, Schutz E, et al. From thrombosis to fibrosis in chronic thromboembolic pulmonary hypertension. Thromb Haemost 2017; 117: 769-783.

17. Morris TA, Marsh JJ, Chiles PG, Auger WR, Fedullo PF, Woods VL, Jr. Fibrin derived from patients with chronic thromboembolic pulmonary hypertension is resistant to lysis. Am J Respir Crit Care Med 2006; 173: 1270-1275.

18. Morris TA, Marsh JJ, Chiles PG, Magana MM, Liang NC, Soler X, et al. High prevalence of dysfibrinogenemia among patients with chronic thromboembolic pulmonary hypertension. Blood 2009; 114: 1929-1936.

19. Marsh JJ, Chiles PG, Liang NC, Morris TA Chronic thromboembolic pulmonary hypertension-associated dysfibrinogenemias exhibit disorganized fibrin structure. Thromb Res 2013; 132 729-734.

20. Quarck R, Wynants M, Verbeken E, Meyns B, Delcroix M. Contribution of inflammation and impaired angiogenesis to the pathobiology of chronic thromboembolic pulmonary hypertension. Eur Respir J 2015; 46: 431-443.

21. Zabini D, Heinemann A, Foris V, Nagaraj C, Nierlich P, Balint Z, et al. Comprehensive analysis of inflammatory markers in chronic thromboembolic pulmonary hypertension patients. Eur Respir J 2014; 44: 951-962.

22. Dorfmuller P, Gunther S, Ghigna MR, Thomas dM, V, Boulate D, Paul JF, et al. Microvascular disease in chronic thromboembolic pulmonary hypertension: a role for pulmonary veins and systemic vasculature. Eur Respir J 2014; 44: 1275-1288.

23. Moser KM, Bloor CM. Pulmonary vascular lesions occurring in patients with chronic major vessel thromboembolic pulmonary hypertension. Chest 1993; 103: 685-692

24. Pietra GG, Capron F, Stewart S, Leone O, Humbert M, Robbins IM, et al. Pathologic assessment of vasculopathies in pulmonary hypertension. J Am Coll Cardiol 2004; 43: 25S-32S.

25. Vonk NA, Westerhof BE, Westerhof N. The Relationship Between the Right Ventricle and its Load in Pulmonary Hypertension. J Am Coll Cardiol 2017; 69: 236-243.

26. Claessen G, La GA, Wielandts JY, Bogaert J, Van CJ, Wuyts W, et al. Exercise pathophysiology and sildenafil effects in chronic thromboembolic pulmonary hypertension. Heart 2015; 101: 637-644.

27. Fedullo PF, Auger WR, Kerr KM, Rubin LJ. Chronic thromboembolic pulmonary hypertension. N Engl J Med 2001; 345: 1465-1472.

28. Klok FA, van Kralingen KW, van Dijk AP, Heyning FH, Vliegen HW, Huisman MV. Prospective cardiopulmonary screening program to detect chronic thromboembolic pulmonary hypertension in patients after acute pulmonary embolism. Haematologica 2010; 95: 970-975.

29. Held M, Hesse A, Gott F, Holl R, Hubner G, Kolb $\mathrm{P}$, et al. A symptom-related monitoring program following pulmonary embolism for the early detection of CTEPH: a prospective observational registry study. BMC Pulm Med 2014; 14: 141.

30. Golpe R, Perez-de-Llano LA, Castro-Anon O, Vazquez-Caruncho M, Gonzalez-Juanatey C, VeresRacamonde A, et al. Right ventricle dysfunction and pulmonary hypertension in hemodynamically stable pulmonary embolism. Respir Med 2010; 104: 1370-1376

31. Klok FA, Tesche C, Rappold L, Dellas C, Hasenfuss $\mathrm{G}$, Huisman MV, et al. External validation of a simple non-invasive algorithm to rule out chronic thromboembolic pulmonary hypertension after acute pulmonary embolism. Thromb Res 2015; 135: 796-801.

32. Giuliani L, Piccinino C, D‘Armini MA, Manganiello S, Ferrarotti L, Balbo PE, et al. Prevalence of undiagnosed chronic thromboembolic pulmonary hypertension after pulmonary embolism. Blood Coagul Fibrinolysis 2014; 25: 649-653.

33. Guerin L, Couturaud F, Parent F, Revel MP, Gillaizeau F, Planquette B, et al. Prevalence of chronic thromboembolic pulmonary hypertension after acute pulmonary embolism. Prevalence of CTEPH after pulmonary embolism. Thromb Haemost 2014; 112: 598-605.

34. Marti D, Gomez V, Escobar C, Wagner C, Zamarro $\mathrm{C}$, Sanchez D, et al. [Incidence of symptomatic and asymptomatic chronic thromboembolic pulmonary hypertension]. Arch Bronconeumol 2010; 46: 628-633.

35. Pesavento R, Filippi L, Palla A, Visona A, Bova C, Marzolo $\mathrm{M}$, et al. Impact of residual pulmonary obstruction on the long-term outcome of patients with pulmonary embolism. Eur Respir J 2017; 49.

36. Gall H, Hoeper MM, Richter MJ, Cacheris W, Hinzmann B, Mayer E. An epidemiological analysis of the burden of chronic thromboembolic pulmonary hypertension in the USA, Europe and Japan. Eur Respir Rev 2017; 26.

37. Ende-Verhaar YM, Cannegieter SC, Vonk NA, Delcroix M, Pruszczyk P, Mairuhu AT, et al. Incidence of chronic thromboembolic pulmonary hypertension after acute pulmonary embolism: a contemporary view of the published literature. Eur Respir J 2017; 49.

38. McIntyre KM, Sasahara AA. The hemodynamic response to pulmonary embolism in patients without prior cardiopulmonary disease. Am J Cardiol 1971; 28: 288-294.

39. Delcroix M, Lang I, Pepke-Zaba J, Jansa P, D‘Armini AM, Snijder R, et al. Long-Term Outcome of Patients With Chronic Thromboembolic Pulmonary Hypertension: Results From an International Prospective Registry. Circulation 2016; 133: 859-871.

40. Lang IM. Chronic thromboembolic pulmonary hypertension--not so rare after all. N Engl J Med 2004; 350: 2236-2238.

41. (41) Ende-Verhaar YM, Huisman MV, Klok FA. To screen or not to screen for chronic thromboembolic pulmonary hypertension after acute pulmonary embolism. Thromb Res 2017; 151: 1-7.

42. Klok FA, Mos IC, van Kralingen KW, Vahl JE, Huisman MV. Chronic pulmonary embolism and pulmonary hypertension. Semin Respir Crit Care Med 2012; 33: 199-204.

43. Lang IM, Simonneau G, Pepke-Zaba JW, Mayer E, Ambroz D, Blanco I, et al. Factors associated with diagnosis and operability of chronic thromboembolic pulmonary hypertension. A case-control study. Thromb Haemost 2013; 110: 83-91.

44. Bonderman D, Wilkens H, Wakounig S, Schafers HJ, Jansa P, Lindner J, et al. Risk factors for chronic thromboembolic pulmonary hypertension. Eur Respir J 2009; 33: 325-331.

45. Bonderman D, Jakowitsch J, Adlbrecht C, Schemper M, Kyrle PA, Schonauer V, et al. Medical conditions increasing the risk of chronic thromboembolic pulmonary hypertension. Thromb Haemost 2005; 93: 512-516. 
46. Frey MK, Alias S, Winter MP, Redwan B, Stubiger G, Panzenboeck A, et al. Splenectomy is modifying the vascular remodeling of thrombosis. J Am Heart Assoc 2014; 3: e000772.

47. Klok FA, Dzikowska-Diduch O, Kostrubiec M, Vliegen HW, Pruszczyk P, Hasenfuss G, et al. Derivation of a clinical prediction score for chronic thromboembolic pulmonary hypertension after acute pulmonary embolism. J Thromb Haemost 2016; 14: 121-128.

48. Pepke-Zaba J, Delcroix M, Lang I, Mayer E, Jansa P, Ambroz D, et al. Chronic thromboembolic pulmonary hypertension (CTEPH): results from an international prospective registry. Circulation 2011; 124: 1973-1981.

49. Wong CL, Szydlo R, Gibbs S, Laffan M. Hereditary and acquired thrombotic risk factors for chronic thromboembolic pulmonary hypertension. Blood Coagul Fibrinolysis 2010; 21: 201-206.

50. Grant PJ, Stickland MH, Booth NA, Prentice CR. Metformin causes a reduction in basal and postvenous occlusion plasminogen activator inhibitor-1 in type 2 diabetic patients. Diabet Med 1991; 8: 361-365.

51. Nagi DK, Yudkin JS. Effects of metformin on insulin resistance, risk factors for cardiovascular disease, and plasminogen activator inhibitor in NIDDM subjects. A study of two ethnic groups. Diabetes Care 1993; 16: 621-629.

52. Lu DY, Huang CC, Huang PH, Chung CM, Lin SJ, Chen JW, et al. Metformin use in patients with type 2 diabetes mellitus is associated with reduced risk of deep vein thrombosis: a non-randomized, pair-matched cohort study. BMC Cardiovasc Disord 2014; 14: 187

53. Stevinson BG, Hernandez-Nino J, Rose G, Kline JA. Echocardiographic and functional cardiopulmonary problems 6 months after first-time pulmonary embolism in previously healthy patients. Eur Heart J 2007; 28: 2517-2524.

54. Kline JA, Steuerwald MT, Marchick MR, Hernandez-Nino J, Rose GA. Prospective evaluation of right ventricular function and functional status 6 months after acute submassive pulmonary embolism: frequency of persistent or subsequent elevation in estimated pulmonary artery pressure. Chest 2009; 136: 1202-1210.

55. Klok FA, van Kralingen KW, van Dijk AP, Heyning FH, Vliegen HW, Huisman MV. Prevalence and potential determinants of exertional dyspnea after acute pulmonary embolism. Respir Med 2010; 104: 1744-1749.

56. Sista AK, Miller LE, Kahn SR, Kline JA. Persistent right ventricular dysfunction, functional capacity limitation, exercise intolerance, and quality of life impairment following pulmonary embolism: Systematic review with meta-analysis. Vasc Med 2017; 22: 37-43.

57. Held M, Kolb P, Grun M, Jany B, Hubner G, Grgic A, et al. Functional Characterization of Patients with Chronic Thromboembolic Disease. Respiration 2016; 91: 503-509.

58. Ribeiro A, Lindmarker P, Johnsson H, JuhlinDannfelt A, Jorfeldt L. Pulmonary embolism: oneyear follow-up with echocardiography doppler and five-year survival analysis. Circulation 1999; 99 1325-1330.

59. Kahn SR, Hirsch AM, Akaberi A, Hernandez P, Anderson DR, Wells PS, et al. Functional and Ex- ercise Limitations After a First Episode of Pulmonary Embolism: Results of the ELOPE Prospective Cohort Study. Chest 2017; 151: 1058-1068.

60. Riedel M, Stanek V, Widimsky J, Prerovsky I. Longterm follow-up of patients with pulmonary thromboembolism. Late prognosis and evolution of hemodynamic and respiratory data. Chest 1982; 81: 151-158.

61. van EJ, den Exter PL, Kaptein AA, Andela CD, Erkens PM, Klok FA, et al. Quality of life after pulmonary embolism as assessed with SF-36 and PEmb-QoL. Thromb Res 2013; 132: 500-505.

62. Hogg K, Kimpton M, Carrier M, Coyle D, Forgie $\mathrm{M}$, Wells P. Estimating quality of life in acute venous thrombosis. JAMA Intern Med 2013; 173 1067-1072.

63. Lukas PS, Neugebauer A, Schnyder S, Biasiutti FD, Krummenacher R, Ferrari ML, et al. Depressive symptoms, perceived social support, and prothrombotic measures in patients with venous thromboembolism. Thromb Res 2012; 130: 374-380.

64. Tavoly M, Utne KK, Jelsness-Jorgensen LP, Wik HS, Klok FA, Sandset PM, et al. Health-related quality of life after pulmonary embolism: a crosssectional study. BMJ Open 2016; 6: e013086.

65. Klok FA, Cohn DM, Middeldorp S, Scharloo M, Buller HR, van Kralingen KW, et al. Quality of life after pulmonary embolism: validation of the PEmb-QoL Questionnaire. J Thromb Haemost 2010; 8: 523-532.

66. Lubberts B, Paulino Pereira NR, Kabrhel C, Kuter DJ, DiGiovanni CW. What is the effect of venous thromboembolism and related complications on patient reported health-related quality of life? A meta-analysis. Thromb Haemost 2016; 116: 417-431.

67. Lukas PS, Krummenacher R, Biasiutti FD, Begre S, Znoj H, von KR. Association of fatigue and psychological distress with quality of life in patients with a previous venous thromboembolic event Thromb Haemost 2009; 102: 1219-1226.

68. Klok FA, Tijmensen JE, Haeck ML, van Kralingen KW, Huisman MV. Persistent dyspnea complaints at long-term follow-up after an episode of acute pulmonary embolism: results of a questionnaire. Eur J Intern Med 2008; 19: 625-629.

69. Ma K, Kahn SR, Hirsch AM, Akaberi A, Anderson DR, Wells PS, et al. N-terminal of prohormone brain natriuretic peptide predicts functional limitation one year following pulmonary embolism: Results from the ELOPE study. Thromb Res 2017; 153: 47-49.

70. Krummenacher R, Lukas PS, Biasiutti FD, Begre S Znoj H, von KR. Independent association of sleep quality, fatigue, and vital exhaustion with platelet count in patients with a previous venous thromboembolic event. Platelets 2009; 20: 566-574.

71. Mathai SC, Ghofrani HA, Mayer E, Pepke-Zaba J, Nikkho S, Simonneau G. Quality of life in patients with chronic thromboembolic pulmonary hypertension. Eur Respir J 2016; 48: 526-537.

72. Roman A, Barbera JA, Castillo MJ, Munoz R, Escribano P. Health-related quality of life in a national cohort of patients with pulmonary arterial hypertension or chronic thromboembolic pulmonary hypertension. Arch Bronconeumol 2013; 49: 181-188.
73. Funabashi S, Kataoka M, Inami T, Kikuchi T, Yanagisawa R, Ishiguro C, et al. Depressive Status in Patients With Chronic Thromboembolic Pulmonary Hypertension. Circ J 2017.

74. Urushibara T, Tanabe N, Suda R, Kato F, Kasai H, Takeuchi T, et al. Effects of Surgical and Medical Treatment on Quality of Life for Patients With Chronic Thromboembolic Pulmonary Hypertension. Circ J 2015; 79: 2696-2702.

75. Jenkins D, Madani M, Fadel E, D'Armini AM, Mayer E. Pulmonary endarterectomy in the management of chronic thromboembolic pulmonary hypertension. Eur Respir Rev 2017; 26.

76. Hoeper MM, Madani MM, Nakanishi N, Meyer B, Cebotari S, Rubin LJ. Chronic thromboembolic pulmonary hypertension. Lancet Respir Med 2014; 2: $573-582$.

77. Taboada D, Pepke-Zaba J, Jenkins DP, Berman M, Treacy CM, Cannon JE, et al. Outcome of pulmonary endarterectomy in symptomatic chronic thromboembolic disease. Eur Respir J 2014; 44: 1635-1645.

78. Ghofrani HA, DAArmini AM, Grimminger F, Hoeper MM, Jansa P, Kim NH, et al. Riociguat for the treatment of chronic thromboembolic pulmonary hypertension. N Engl J Med 2013; 369: 319-329.

79. Simonneau G, D’Armini AM, Ghofrani HA, Grimminger F, Jansa P, Kim NH, et al. Predictors of long-term outcomes in patients treated with riociguat for chronic thromboembolic pulmonary hypertension: data from the CHEST-2 open-label, randomised, long-term extension trial. Lancet Respir Med 2016; 4: 372-380.

80. Simonneau G, D’Armini AM, Ghofrani HA, Grimminger F, Hoeper MM, Jansa P, et al. Riociguat for the treatment of chronic thromboembolic pulmonary hypertension: a long-term extension study (CHEST-2). Eur Respir J 2015; 45: 1293-1302.

81. Konstantinides SV, Torbicki A, Agnelli G, Danchin N, Fitzmaurice D, Galie N, et al. 2014 ESC guidelines on the diagnosis and management of acute pulmonary embolism. Eur Heart J 2014; 35: 3033-3069k.

82. Olsson KM, Wiedenroth CB, Kamp JC, Breithecker A, Fuge J, Krombach GA, et al. Balloon pulmonary angioplasty for inoperable patients with chronic thromboembolic pulmonary hypertension: the initial German experience. Eur Respir J 2017; 49.

83. Lang I, Meyer BC, Ogo T, Matsubara H, Kurzyna M, Ghofrani HA, et al. Balloon pulmonary angioplasty in chronic thromboembolic pulmonary hypertension. Eur Respir Rev 2017; 26.

84. Akizuki M, Serizawa N, Ueno A, Adachi T, Hagiwara N. Effect of Balloon Pulmonary Angioplasty on Respiratory Function in Patients With Chronic Thromboembolic Pulmonary Hypertension. Chest 2017; 151: 643-649.

85. Andreassen AK, Ragnarsson A, Gude E, Geiran O, Andersen R. Balloon pulmonary angioplasty in patients with inoperable chronic thromboembolic pulmonary hypertension. Heart 2013; 99: $1415-1420$

86. Fukui S, Ogo T, Goto Y, Ueda J, Tsuji A, Sanda Y, et al. Exercise intolerance and ventilatory inefficiency improve early after balloon pulmonary angioplasty in patients with inoperable chronic throm- 
boembolic pulmonary hypertension. Int J Cardiol 2015; 180: 66-68.

87. Voorburg JA, Cats VM, Buis B, Bruschke AV. Balloon angioplasty in the treatment of pulmonary hypertension caused by pulmonary embolism. Chest 1988; 94: 1249-1253.

88. Noack F, Schmidt B, Amoury M, Stoevesandt D, Gielen S, Pflaumbaum B, et al. Feasibility and safety of rehabilitation after venous thromboembolism. Vasc Health Risk Manag 2015; 11: 397-401.

89. Lakoski SG, Savage PD, Berkman AM, Penalosa L, Crocker A, Ades PA, et al. The safety and efficacy of early-initiation exercise training after acute venous thromboembolism: a randomized clinical trial. J Thromb Haemost 2015; 13: 1238-1244.

90. Nagel C, Prange F, Guth S, Herb J, Ehlken N, Fischer $\mathrm{C}$, et al. Exercise training improves exercise capacity and quality of life in patients with inoperable or residual chronic thromboembolic pulmonary hypertension. PLoS One 2012; 7: e41603.

91. Inagaki T, Terada J, Tanabe N, Kawata N, Kasai H, Sugiura T, et al. Home-based pulmonary rehabilitation in patients with inoperable or residual chronic thromboembolic pulmonary hypertension: a preliminary study. Respir Investig 2014; 52 : 357-364.

92. Fukui S, Ogo T, Takaki H, Ueda J, Tsuji A, Morita $Y$, et al. Efficacy of cardiac rehabilitation after bal- loon pulmonary angioplasty for chronic thromboembolic pulmonary hypertension. Heart 2016; 102: 1403-1409.

93. Konstantinides SV, Barco S, Rosenkranz S, Lankeit M, Held M, Gerhardt F, et al. Late outcomes after acute pulmonary embolism: rationale and design of FOCUS, a prospective observational multicenter cohort study. J Thromb Thrombolysis 2016; 42: 600-609.

94. Klok FA, Tesche C, Rappold L, Dellas C, Hasenfuss G, Huisman MV, et al. External validation of a simple non-invasive algorithm to rule out chronic thromboembolic pulmonary hypertension after acute pulmonary embolism. Thromb Res 2015; 135: 796-801.

95. Klok FA, Surie S, Kempf T, Eikenboom J, van Straalen JP, van Kralingen KW, et al. A simple noninvasive diagnostic algorithm for ruling out chronic thromboembolic pulmonary hypertension in patients after acute pulmonary embolism. Thromb Res 2011; 128: 21-26.

96. Rolving N, Brocki BC, Mikkelsen HR, Ravn P, Bloch-Nielsen JR, Frost L. Does an 8-week homebased exercise program affect physical capacity, quality of life, sick leave, and use of psychotropic drugs in patients with pulmonary embolism? Study protocol for a multicenter randomized clinical trial. Trials 2017; 18: 245 . 